\title{
A Non-alternant Aromatic Belt: Methylene-bridged [6]Cycloparaphenylene Synthesized from Pillar[6]arene
}

\author{
Yuanming Li, † Yasutomo Segawa, ${ }^{\ddagger}, \#, \S, \$$ Akiko Yagi, ${ }^{\ddagger}$ and Kenichiro Itami*,+,‡,\# \\ †Institute of Transformative Bio-Molecules (WPI-ITbM), Nagoya University, Chikusa, Nagoya 464-8602, Japan \\ ${ }^{\ddagger}$ Graduate School of Science, Nagoya University, Chikusa, Nagoya 464-8602, Japan \\ \#JST-ERATO, Itami Molecular Nanocarbon Project, Nagoya University, Chikusa, Nagoya 464-8602, Japan \\ §Institute for Molecular Science, Myodaiji, Okazaki, 444-8787, Japan \\ \$Department of Structural Molecular Science, SOKENDAI (The Graduate University for Advanced Studies), Myodaiji, \\ Okazaki, 444-8787, Japan.
}

\begin{abstract}
The synthesis, structure, and properties of methylene-bridged [6]cycloparaphenylene ([6]CPP), a non-alternant aromatic belt, are described. This belt-shaped methylene-bridged [6]CPP, in which each phenylene unit is tethered to its neighbors by methylene bridges, was constructed through six-fold intramolecular nickel-mediated aryl-aryl coupling of triflate-functionalized pillar[6]arene in 15\% isolated yield. Compared with the analogous [6]CPP, the methylene bridges coplanarize neighboring paraphenylene units and enhance the degree of $\pi$-conjugation, resulting in a significant decrease in energy gap. Moreover, the incorporation of small molecules in the defined pocket of methylene-bridged [6]CPP makes it an attractive supramolecular architecture. Methylene-bridged [6]CPP is characterized by high internal strain energy reaching $110.2 \mathrm{kcal} \cdot \mathrm{mol}^{-1}$, attributed to its restricted structure. This work not only exhibits an efficient strategy to construct a new family of aromatic belt, but also showcases their properties, which combine the merits of CPPs and pillararenes.
\end{abstract}

\section{Introduction}

The development of novel curved $\pi$-conjugated nanocarbon structures is of particular interest and is critical in discovering new organic materials. ${ }^{1}$ Belt-shaped aromatic compounds are one of the most important classes of radial $\pi$-conjugated nanocarbon molecules, ${ }^{2}$ and have been the subject of extensive research ranging from synthetic methodologies to materials science. ${ }^{3}$ Compared to single-stranded paraphenylenes, ladder-type paraphenylenes (LPPs) (Figure $1 \mathrm{~A})^{4}$ have a ribbon-like geometry and favorable properties such as enhanced $\pi$ conjugation, high photoluminescent efficiency, and remarkable hole mobility. ${ }^{5}$ These characteristics make LPPs attractive materials for potential use in organic electronic devices. This encouraged us to pursue the synthesis of methylene-bridged cycloparaphenylene (CPP) as a new type of non-alternant aromatic belt (Figure 1B), in which the cyclic paraphenylene chain is ladderized by methylene bridges. Due to the intrinsic flexibility of CPPs, particularly their free rotation of phenylene units around the phenylene-phenylene linkage, ${ }^{6} \mathrm{CPPs}$ possess torsion angles of ca. $27-35^{\circ}$ between phenylene units. ${ }^{7}$ Therefore, the structure of methylene-bridged CPPs possessing enhanced $\pi$-conjugation and well-defined conformations would be of great interest, in addition to presenting a fascinating synthetic challenge.
(A)
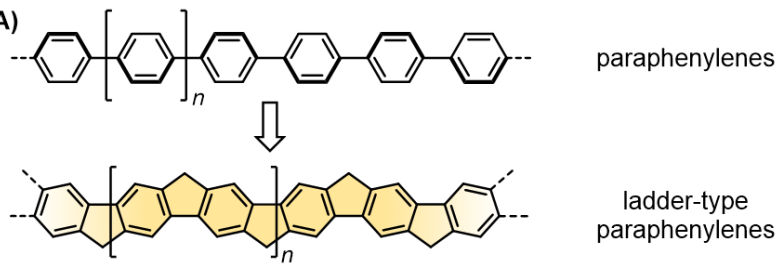

ladder-type paraphenylenes

(B)

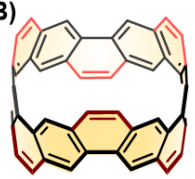

carbon nanobelt $([6,6] \mathrm{CNB})$

(C)

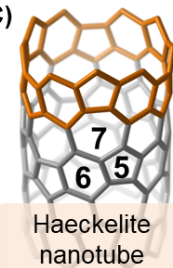

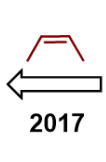

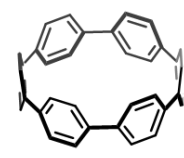

[6]CPP

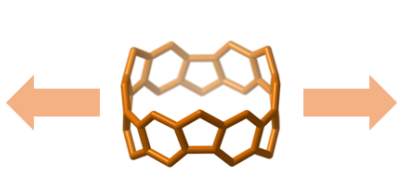

methylene-bridged [6]CPP

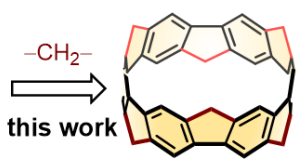
(methylene-bridged [6]CPP)

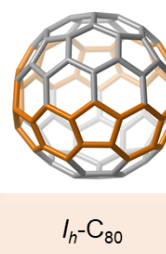

non-alternant aromatic belt

Figure 1. (A) Structures of paraphenylenes and laddertype paraphenylenes. (B) Aromatic belts having [6]CPP skeleton. (C) The segment of nanotube and fullerenes. 
The bottom-up synthesis of an aromatic belt with a CPP skeleton has rarely been explored to date. In 2017, our group used ethenylene bridges to connect phenylene units to create a fully fused and conjugated carbon nanobelt $\left([6,6]\right.$ CNB, Figure 1B). ${ }^{8}$ Subsequently, Chi, Miao, and coworkers achieved the synthesis of phenylene-bridged carbon nanobelt (see Figure S28). ${ }^{9}$ Very recently, Tanaka's group prepared the $\mathrm{CH}_{2} \mathrm{O}$-bridged [8]CPP (see Figure S28). ${ }^{10}$ Although partially fused CPPs by methylene bridges, i.e. cyclofluorene, have been reported, ${ }^{11}$ the belt-shaped fully methylene-bridged CPPs still represent a synthetic challenge. The construction of the backbone is the key to achieving the synthesis of methylene-bridged CPPs. Inspired by Vögtle and co-workers' pioneering concept to access CPPs from pre-existing macrocycles, ${ }^{12}$ we herein report the synthesis of methylene-bridged [6]CPP using triflate-functionalized pillar[6]arene as a macrocyclic precursor, ${ }^{13}$ through six-fold nickel-mediated Yamamoto coupling. The enforced coplanarity of methylene-bridged [6]CPP and shrinking diameter caused by the bridges results in relatively high strain energy $\left(110.2 \mathrm{kcal} \cdot \mathrm{mol}^{-1}\right)$. Furthermore, methylene-bridged [6]CPP represents a belt segment of a Haeckelite nanotube possessing pentagonhexagon-heptagon ring systems, as well as a segment of fullerenes such as $I_{h}$ - 8 80 (Figure 1C). ${ }^{14}$

\section{Results and Discussion}

\section{Synthesis}

Pillararene is a pillar-shaped macrocyclic host synthesized in 2008 by Ogoshi and coworkers. ${ }^{15}$ Due to its methylene-bridged macrocyclic arene skeleton, we envisioned that pillar[6] $\operatorname{arene}^{16}$ could serve as a suitable macrocyclic precursor for the synthesis of methylenebridged [6]CPP. The synthetic route to the target product is summarized in Scheme 1. Pillar[6] arene was prepared in one step from commercially available 1,4diethoxybenzene. ${ }^{17}$ Taking advantage of the ethoxy groups of pillar[6]arene, the intramolecular aryl-aryl coupling of aryl triflates to provide the CPP backbone could be easily imagined based on our previous results. ${ }^{8 a, b}$ With this in mind, pillar[6]arene triflate 3 was readily prepared through ether cleavage followed by triflation in 39\% isolated yield over two steps. ${ }^{18}$ With $\mathbf{3}$ in hand, we investigated the key step of the aryl-aryl coupling of aryl triflate. Based on previous reports using an $\mathrm{ArBr} / \mathrm{Ni}(\operatorname{cod})_{2} / 2,2$ '-bipyridyl system, ${ }^{8 b, 19}$ we investigated the effect of ligands and other reaction parameters in the aryl-aryl coupling reaction using $\mathbf{3}$ as the pseudohalide component (see Table S1 for further details). We found that pillar[6]arene triflate $\mathbf{3}$ reacted successfully with 12 equivalents of $\mathrm{Ni}(\mathrm{cod})_{2}$ and 2,2'-bipyridyl (bpy) at $80^{\circ} \mathrm{C}$ for 2 hours to produce the fully fused target belt $\mathbf{4}$ in 15\% isolated yield as a red solid. Compound $\mathbf{4}$ is soluble in dichloromethane (up to 20 $\mathrm{mg} / \mathrm{mL}$ ) and $\mathrm{CS}_{2}$, and shows sufficient stability in solution to enable full characterization. This synthetic strategy offers a new and rapid approach to access a new type of aromatic belt.
Scheme 1. Synthetic Route of Methylene-bridged [6]CPP ${ }^{a}$

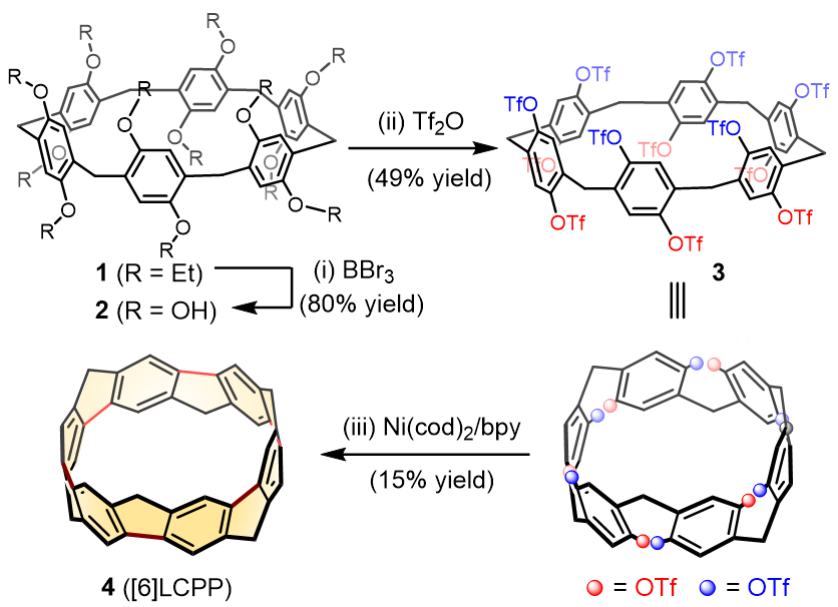

${ }^{a}$ Reaction conditions: (i) 1 (1.0 equiv, $12.5 \mathrm{mM}$ ), $\mathrm{BBr}_{3}$ (40 equiv), $\mathrm{CHCl}_{3}$, room temperature (rt), $24 \mathrm{~h}$. (ii) $\mathrm{Tf}_{2} \mathrm{O}$ (16 equiv), pyridine (18 equiv), $\mathrm{CH}_{2} \mathrm{Cl}_{2}, \mathrm{rt}, 24 \mathrm{~h}$. (iii) 3 ( 1.0 equiv, $3.0 \mathrm{mM}$ ), $\mathrm{Ni}(\mathrm{cod})_{2}$ (12 equiv), 2,2'-bipyridyl (12 equiv), $\mathrm{N}$ methyl-2-pyrrolidone (NMP), $80{ }^{\circ} \mathrm{C}, 2 \mathrm{~h}$.

\section{Nuclear Magnetic Resonance Analysis}

In the ${ }^{1} \mathrm{H}$ NMR spectrum in $\mathrm{CDCl}_{3}$ at $25{ }^{\circ} \mathrm{C}$, compound 4 showed one singlet of aromatic hydrogen atoms at 7.86 ppm and two doublets of geminal hydrogen atoms at 4.09 and $4.29 \mathrm{ppm}$, corresponding with the $D_{3 \mathrm{~d}}$ symmetry of the belt structure (Figure 2). According to the calculated chemical shifts by using GIAO B3LYP/6$311+G(2 d, p) / / B 3 L Y P / 6-31 G(d)$ level of theory (see Table S5), the signals appearing at 4.09 and $4.29 \mathrm{ppm}$ can be assigned to the inner and the outer hydrogen atoms respectively. The ${ }^{13} \mathrm{C}$ NMR analysis disclosed four sets of nonequivalent carbon atoms, again associated with the $D_{3 \mathrm{~d}}$ symmetry of 4 .

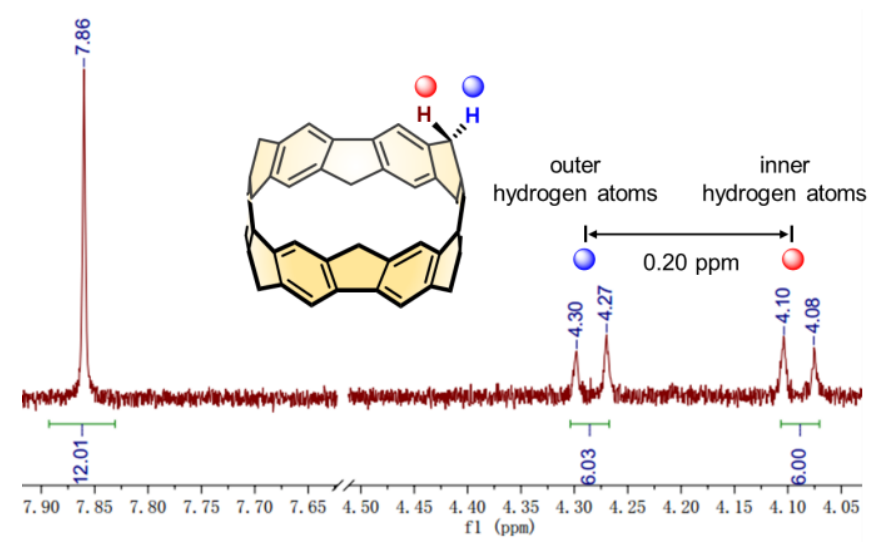

Figure 2. ${ }^{1} \mathrm{H}$ NMR spectrum of $4\left(600 \mathrm{MHz}, \mathrm{CDCl}_{3}, 25^{\circ} \mathrm{C}\right)$. 


\section{X-ray Crystal Structures}

The belt-shaped structure of $\mathbf{4}$ was confirmed by single crystal X-ray diffraction analysis (Figure 3) and was further explored using gas-phase DFT calculations. Slow diffusion of $n$-hexane into a $\mathrm{CH}_{2} \mathrm{Cl}_{2}$ solution of $\mathbf{4}$ at room temperature resulted in the formation of red single crystals with both solvent molecules ( $n$-hexane and $\mathrm{CH}_{2} \mathrm{Cl}_{2}$ ) as a ternary cocrystal (Figure 3A and 3C). Compound $\mathbf{4}$ exhibits a small elliptic deformation of the cylindrical shape in the crystal structure (Figure 3B). Interestingly, the phenylene units of [6]CPP linked with methylene bridges form a condensed belt structure because of the shorter length (Figure S2), resulting in a shrinking diameter (7.758 $\AA$ ), considerably less than that of [6]CPP $(8.072 \AA)^{20}$ and $[6,6]$ CNB $(8.053 \AA)$ (Table 1). On the other hand, the dihedral angles between the adjacent phenylene units are almost zero (Figure 3B, cf. [6]CPP, $\left.27.4^{\circ}\right) .^{7}$ The symmetrically independent $\mathrm{C}-\mathrm{C}$ bond lengths of the six-membered rings are 1.408, 1.395, and $1.384 \AA$ (Table S3). These approximately equivalent bond lengths imply that a benzenoid structure is still preserved in methylene-bridged [6]CPP. Moreover, the C-C single bond connecting the phenylene units in 4 (average $1.478 \AA$ ) is shorter than that of [6]CPP $(1.489 \AA)^{21}$ and longer than the analogous bond in $[6,6]$ CNB $(1.464 \AA)$. Furthermore, compound 4 contains phenylene units that are less bent (Table S3, averaged bent angle, $8.4^{\circ}$ ) than that of corresponding [6]CPP $\left(12.5^{\circ}\right)$. These results are in good agreement with the structure optimized by DFT calculations (see Table S3). This new belt-shaped nanocarbon structure would be of great interest as an element of supramolecular architecture.

The packing mode of $\mathbf{4}$ in the crystal is also interesting. Unlike the tubular packing structure of [6]CPP obtained at room temperature, ${ }^{21}$ the crystal packing of 4 results in a herringbone pattern in the $\left[\begin{array}{lll}0 & \overline{1} & 1\end{array}\right]$ plane with $\mathrm{CH}-\pi$ interactions between adjacent molecules (Figure 3C upper left, and Figure S1). The different complexes of compound 4 are packed in an alternating fashion between layers in the [001] (ab) plane (Figure 3C, bottom-left). Intriguingly, the methylene hydrogen atoms prevent efficient $\pi-\pi$ stacking. Therefore, no clear intermolecular $\pi-\pi$ interaction was observed. Instead, close $\mathrm{CH}-\pi$ interactions (2.821-2.862 Å) were observed (Figure 3C, right).

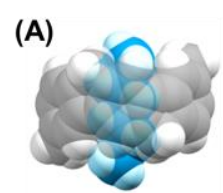

(side view)

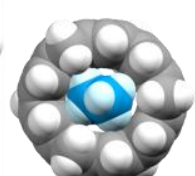

(top view)

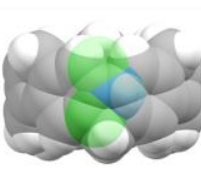

(side view)

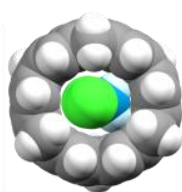

(top view)

$4 \supset n$-hexane

(B)

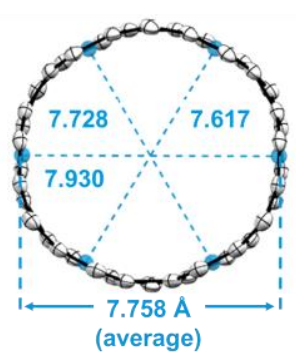

$$
4 \supset \mathrm{CH}_{2} \mathrm{Cl}_{2}
$$

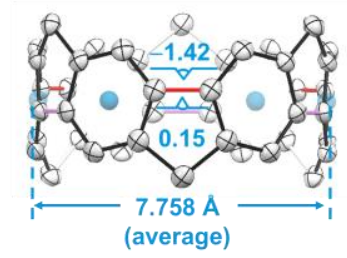

(C)

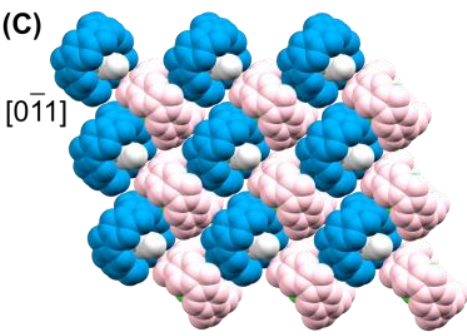

4 (blue) $\supset n$-hexane (grey) 4 (pink) $\supset \mathrm{CH}_{2} \mathrm{Cl}_{2}$ (green)

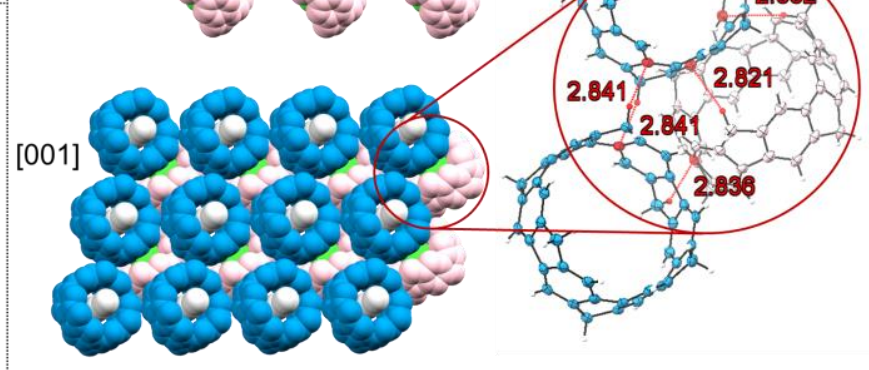

Figure 3. (A) X-ray structures of crystallographically independent molecules of 4 incorporating $n$-hexane (left) and dichloromethane (right). The solvent molecules are disordered on stereocenters (carbon: blue, hydrogen: light blue, chlorine: green). (B) ORTEP drawing of $\mathbf{4} \cdot n$-hexane with $50 \%$ thermal probability (hydrogen atoms and $n$-hexane are omitted for clarity.). The diameter was measured as the distance between the two central phenylene units located at opposite sides. The internal and external dihedral angles are $0.15^{\circ}$ and $-1.42^{\circ}$, respectively. (C) The packing structure of 4 . Hydrogen atoms are omitted for clarity. Inset: Distances between the hydrogen and the nearest aromatic carbon.

\section{Strain Energy}

Based on homodesmotic reaction schemes, ${ }^{6}$ the ring strain energies of compound 4 corresponding to the distortion caused by the formation of methylene-bridged [6]CPP were calculated to be $110.2 \mathrm{kcal} \cdot \mathrm{mol}^{-1}$ at the B3LYP/6-31G(d) level (Scheme 2). This value is higher than the analogous energy calculated for [6]CPP $\left(96.9 \mathrm{kcal} \cdot \mathrm{mol}^{-}\right.$ $\left.{ }^{1}\right),{ }^{6}$ and lower than that of $[6,6] \mathrm{CNB}\left(119.5 \mathrm{kcal} \cdot \mathrm{mol}^{-1}\right) .{ }^{8 a}$ The higher strain energy of compound 4 compared to [6]CPP is attributed largely to the condensed structure with a smaller diameter. The strain energy of even-numbered methylenebridged $[n]$ CPPs was also estimated (see Scheme S3 and Figure S26).
Scheme 2. Homodesmotic Reactions to Calculate Strain Energy of Methylene-bridged $[n]$ CPP.

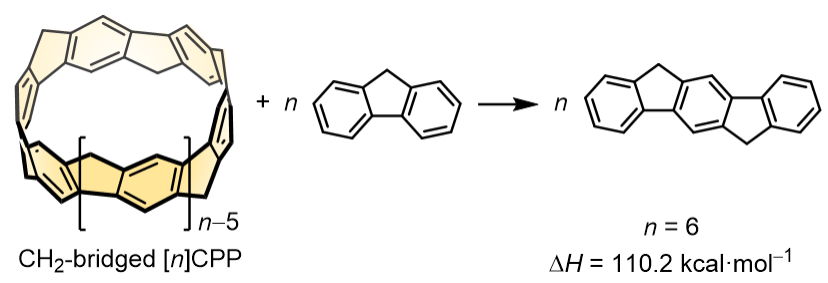


Photophysical Properties and Frontier Molecular Orbitals

To gain insight into the effect of the methylene bridges on $\mathbf{4}$, the photophysical properties of compound $\mathbf{4}$ were measured (Figure 4A and Figure S27). In comparison to [6]CPP, which exhibits a major absorption band at $339 \mathrm{~nm}$ and much weaker peaks at $400-500 \mathrm{~nm}$, compound 4 shows one major absorption band at $347 \mathrm{~nm}$ with one weaker band at $370 \mathrm{~nm}$ in the $\mathrm{CH}_{2} \mathrm{Cl}_{2}$ solution. A much weaker absorption extending up to $600 \mathrm{~nm}$ is also observed, and detectable fluorescence was not observed from $\mathbf{4}$ in $\mathrm{CH}_{2} \mathrm{Cl}_{2}$ solution. This behavior is similar to that of small CPPs, such as [6]CPP, which has no detectable fluorescence.

For further understanding of the absorption spectrum, TD-DFT calculation of compound $\mathbf{4}$ was carried out at the B3LYP/6-31G(d) level of theory. Compound 4 has degenerate HOMO-1/HOMO-2 and degenerate LUMO+2/LUMO+3 $($ HOMO = highest occupied molecular orbital, LUMO = lowest unoccupied molecular orbital, Figure 4B). The major absorption band can be assigned to a combination of the HOMO-1 and HOMO-2 to LUMO, and the HOMO to LUMO+2 and LUMO+3 transitions (Figure 4B). This transition is different from the assignments for [6]CPP21a and $[6,6] \mathrm{CNB}$ (see Table S6 for comparison). The weak absorption at $450-600 \mathrm{~nm}$, associated with the symmetry-forbidden HOMO-LUMO transition, was also observed in $[6,6]$ CNB reflecting their structural rigidity, whereas the corresponding band of [6]CPP is relatively high owing to its conformational flexibility. The non-emission property of $\mathbf{4}$ can also be attributed to the symmetrically forbidden $S_{1} \rightarrow S_{0}$ transition. ${ }^{22}$ The energy levels of the calculated frontier molecular orbitals of $\mathbf{4}$ are shown in Figure 4B. The HOMO and LUMO of $\mathbf{4}$ are delocalized over the phenylene units.

Comparing 4 to [6]CPP, the LUMO and HOMO energies are raised by $0.04 \mathrm{eV}$ and $0.52 \mathrm{eV}$, respectively, leading to an energy gap of $2.66 \mathrm{eV}, 0.48 \mathrm{eV}$ narrower than that of [6]CPP and $0.29 \mathrm{eV}$ narrower than that of $[6,6] \mathrm{CNB}$ (Table 1). This is consistent with the bathochromic shift in the absorption spectra of 4 . This calculated narrow HOMO-LUMO gap of $\mathbf{4}$ is comparable to that of $\mathrm{C}_{60}(2.77$ $\mathrm{eV}),{ }^{23}$ which suggests that $\mathbf{4}$ would be a prominent organic material for optoelectronic devices. Furthermore, the energy gap between the $S_{2}$ and $S_{1}$ of $4(1.1 \mathrm{eV})$ is significantly larger than that of $[6,6] \mathrm{CNB}(0.24 \mathrm{eV}$ ) (see Table $\mathbf{S 6}$ for comparison between 4 and $[6,6] \mathrm{CNB})$.
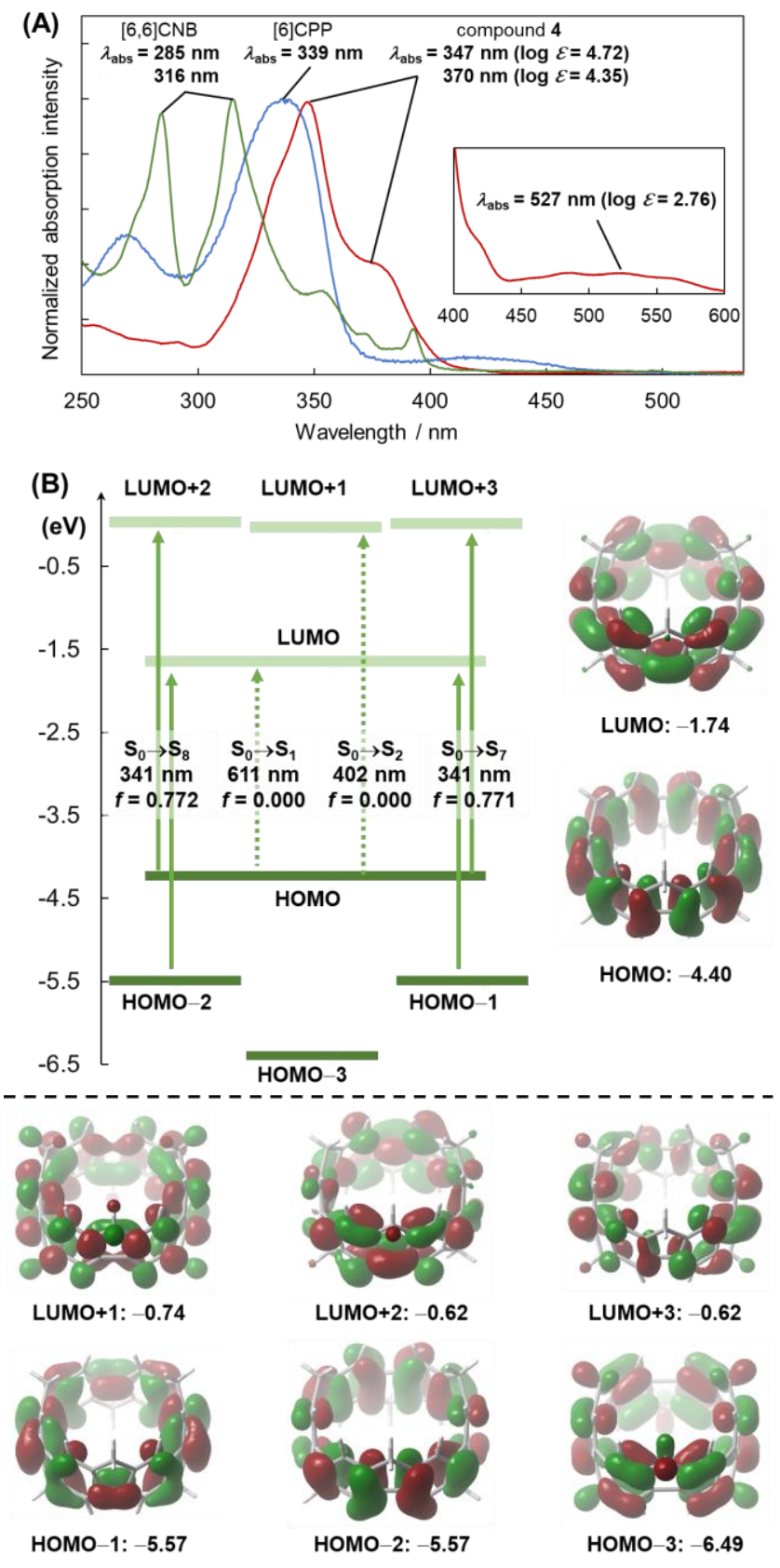

Figure 4. (A) UV/vis absorption spectra (4: red line; [6]CPP: blue line; [6,6]CNB: green line) in $\mathrm{CH}_{2} \mathrm{Cl}_{2}$. A weakly absorbing region (inset) was measured at high concentration. (B) Energy diagrams and frontier molecular orbitals of $\mathbf{4}$ calculated at the B3LYP/6-31G(d) level of theory (unit: eV).

Next, the energies of frontier orbitals of even-numbered $[n]$ LPPs, $[n]$ CPPs, and methylene-bridged $[n]$ CPPs are plotted in Figure 5 (also see Figures S5-S25). Methylenebridged $[n]$ CPPs have increasing HOMO energies and decreasing LUMO energies (narrowing HOMO-LUMO gaps) with a decreased number of benzene rings $(n)$. This size dependency of the HOMO/LUMO energies of methylenebridged $[n]$ CPPs is similar to those of $[n] \mathrm{CPP}$ and in direct contrast to $[n]$ LPPs. $^{24}$ The size dependency of the LUMO level of methylene-bridged $[n]$ CPPs is smaller than that of $[n]$ CPPs, which is similar to the previous report on the $[n]$ CPPs in which phenylene-phenylene torsion angles are restricted. ${ }^{7}$ Importantly, owing to the bending effect, ${ }^{7}$ 
methylene-bridged CPPs have narrower HOMO-LUMO gaps than very long $[n]$ LPPs, which possess high HOMO level compared with $[n]$ CPPs. The readily available high HOMO level and narrow HOMO-LUMO gap of methylene-bridged $[n]$ CPPs highlight their potential utility as organic semiconducting materials.

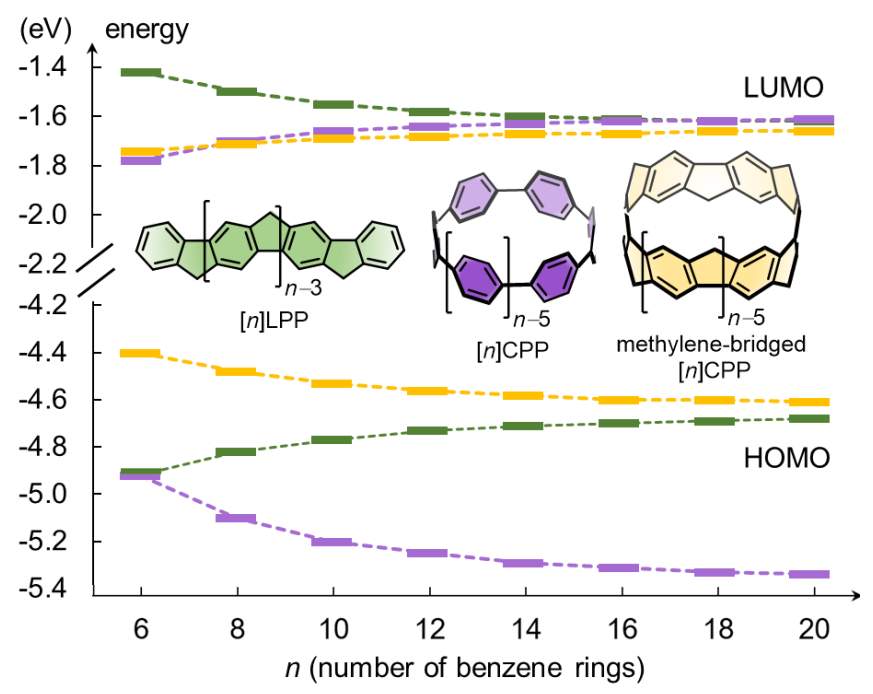

Figure 5. HOMO and LUMO energies of even-numbered $[n]$ LPPs (green dotted line), $[n]$ CPPs (purple dotted line), and methylene-bridged $[n]$ CPPs (orange dotted line) calculated at the B3LYP/6-31G(d) level of theory.

\section{Comparison among 4, [6]CPP, and [6,6]CNB}

Methylene-bridged [6]CPP (4) represents an exciting new addition to the family of carbon nanoring and nanobelt. Moreover, the present study allows us to better understand the structure-property relationship around these molecular entities. Representative parameters of 4, [6]CPP, and $[6,6]$ CNB are summarized in Table 1 (see Table S8 for the detailed comparison). Compared with [6]CPP and [6,6]CNB, methylene-bridged [6]CPP containing alternating five- and six-membered rings gives rise to the smallest diameter, highest HOMO energy, and narrowest HOMO-LUMO gap. These unique geometric features and physical properties make methylene-bridged $[n]$ CPPs a brand-new aromatic belt.

Table 1. Comparison among 4, [6]CPP, and [6,6]CNB.

\begin{tabular}{|c|c|c|c|}
\hline compound $^{a}$ & 4 & [6]CPP & {$[6,6] \mathrm{CNB}$} \\
\hline diameter $(\AA)^{b}$ & 7.758 & 8.072 & 8.053 \\
\hline$C-C(\AA)^{c}$ & 1.478 & 1.489 & 1.464 \\
\hline HOMO $(\mathrm{eV})^{d}$ & -4.40 & -4.92 & -4.92 \\
\hline LUMO $(\mathrm{eV})^{d}$ & -1.74 & -1.78 & -1.97 \\
\hline $\begin{array}{l}\text { HOMO-LUMO } \\
\text { gap }(\mathrm{eV})\end{array}$ & 2.66 & 3.14 & 2.95 \\
\hline $\begin{array}{l}\text { strain energy } \\
\left(\mathrm{kcal} \cdot \mathrm{mol}^{-1}\right)^{e}\end{array}$ & 110.2 & 96.9 & 119.5 \\
\hline
\end{tabular}

bond connecting the neighboring phenylene units. $d$ Frontier molecular orbitals calculated at the B3LYP/6-31G(d) level of theory. ${ }^{e}$ The strain energy data of $[6] \mathrm{CPP}^{6}$ and $[6,6] \mathrm{CNB}^{8 a}$ were taken from references.

\section{Conclusions}

In summary, we have established an efficient synthetic strategy to synthesize the first methylene-bridged [6]CPP through the use of pillar[6]arene as an easily accessible macrocyclic precursor. The product is synthesized through an efficient six-fold intramolecular nickel-mediated Yamamoto coupling. The belt-shaped structure was determined by single-crystal X-ray structure analysis. A particular advantage of this methylene-bridged CPPs over pristine CPPs is its enhancement of $\pi$-conjugation along the backbone by reducing the torsion angle between neighboring phenylene units, which has been proven as an efficient strategy to reduce the energy gap. Moreover, the incorporation of small molecules in the defined pocket of methylene-bridged [6]CPP also paves the way for its application in supramolecular chemistry. This work not only exhibits an efficient strategy to construct a new family of aromatic belt, but also showcases their properties, which combine the merits of CPPs and pillararenes. In a broader perspective, further oxidation of methylene-bridged [6]CPP to form the fully conjugated and lower energy gap belt is also attractive for potential future applications in nanoelectronics and photonics. ${ }^{25}$ Further exploration in this area is ongoing in our laboratory.

\section{ASSOCIATED CONTENT}

\section{Supporting Information}

The Supporting Information is available free of charge on the ACS Publications website.

Synthetic procedures, characterization data, details of the photophysical measurements, and NMR spectra of new compounds (PDF)

Cartesian coordinates of optimized structures (XYZ)

$\mathrm{X}$-ray crystallographic data for 4 (CIF)

\section{AUTHOR INFORMATION}

\section{Corresponding Author}

*E-mail: itami@chem.nagoya-u.ac.jp (K.I.).

\section{ORCID}

Yuanming Li: 0000-0003-3180-1305

Yasutomo Segawa: 0000-0001-6439-8546

Akiko Yagi: 0000-0003-2941-4357

Kenichiro Itami: 0000-0001-5227-7894

Notes

The authors declare no competing financial interest.

\section{ACKNOWLEDGMENT}

This work was supported by the ERATO program from JST (JPMJER1302 to K.I.), JSPS KAKENHI (grant numbers $19 H 05463$ to K.I., JP19H02701 and JP19K22183 to Y.S., and 
19K15537 to A.Y.) and CREST program from JST (JPMJCR19R1 to A.Y.). We thank Mr. Wataru Matsuoka for X-ray crystal structure analysis, and Dr. Iain A. Stepek, Dr. Kwan Yin Cheung, and Dr. Kenta Kato for constructive criticism of the manuscript. Y.L. is a recipient of JSPS Postdoctoral Fellowships for Research in Japan. Calculations were performed using the resources of the Research Center for Computational Science, Okazaki, Japan. ITbM is supported by the World Premier International Research Center Initiative (WPI), Japan.

\section{REFERENCES}

(1) (a) Fragments of Fullerenes and Carbon Nanotubes: Designed Synthesis, Unusual Reactions, and Coordination Chemistry; Petrukhina, M. A., Scott, L. T., Eds.; John Wiley \& Sons: Hoboken, NJ, 2012. (b) Wu, Y.-T.; Siegel, J. S. Synthesis, Structures, and Physical Properties of Aromatic Molecular-Bowl Hydrocarbons. In Polyarenes $I$, Siegel, J. S.; Wu, Y.-T. Eds. Springer Berlin Heidelberg: Berlin, Heidelberg, 2014; pp 63-120. (c) Narita, A.; Wang, X.-Y.; Feng, X.; Müllen, K. New advances in nanographene chemistry. Chem. Soc. Rev. 2015, 44, 6616-6643. (d) Segawa, Y.; Ito, H.; Itami, K. Structurally uniform and atomically precise carbon nanostructures. Nat. Rev. Mater. 2016, 1, 15002. (e) Pun, S. H.; Miao, Q. Toward Negatively Curved Carbons. Acc. Chem. Res. 2018, 51, 1630-1642. (f) Bols, P. S.; Anderson, H. L. Template-Directed Synthesis of Molecular Nanorings and Cages. Acc. Chem. Res. 2018, 51, 2083-2092. (g) Segawa, Y.; Levine, D. R.; Itami, K. Topologically Unique Molecular Nanocarbons. Acc. Chem. Res. 2019, 52, 2760 2767. (h) Majewski, M. A.; Stępień, M. Bowls, Hoops, and Saddles: Synthetic Approaches to Curved Aromatic Molecules. Angew. Chem., Int. Ed. 2019, 58, 86-116. (i) Leonhardt, E. J.; Jasti, R. Emerging applications of carbon nanohoops. Nat. Rev. Chem. 2019, 3, 672-686.

(2) (a) Iyoda, M.; Yamakawa, J.; Rahman, M. J. Conjugated Macrocycles: Concepts and Applications. Angew. Chem., Int. Ed. 2011, 50, 10522-10553. (b) Darzi, E. R.; Jasti, R. The dynamic, size-dependent properties of [5][12]cycloparaphenylenes. Chem. Soc. Rev. 2015, 44, 6401-6410. (c) Lewis, S. E. Cycloparaphenylenes and related nanohoops. Chem. Soc. Rev. 2015, 44, 22212304. (d) Yamago, S.; Kayahara, E.; Hashimoto, S. Cycloparaphenylenes and Carbon Nanorings. In Polycyclic Arenes and Heteroarenes: Synthesis, Properties, and Applications; Miao, Q., Ed.; John Wiley \& Sons: Chichester, U.K., 2015; pp 143-162. (e) Guo, L.; Yang, X.; Cong, H. Synthesis of Macrocyclic Oligoparaphenylenes Derived from Anthracene Photodimer. Chin. J. Chem. 2018, 36, 1135-1138. (f) Lu, D.; Huang, Q.; Wang, S.; Wang, J.; Huang, P.; Du, P. The Supramolecular Chemistry of Cycloparaphenylenes and Their Analogs. Front. Chem. 2019, 7: 668.

(3) (a) Kawase, T.; Kurata, H. Ball-, Bowl-, and BeltShaped Conjugated Systems and Their Complexing Abilities: Exploration of the Concave-Convex $\pi-\pi$ Interaction. Chem. Rev. 2006, 106, 5250-5273. (b) Tahara, K.; Tobe, Y. Molecular Loops and Belts. Chem. Rev. 2006, 106, 5274-5290. (c) Gleiter, R.; Esser, B.; Kornmayer, S. C. Cyclacenes: Hoop-Shaped Systems Composed of Conjugated Rings. Acc. Chem. Res. 2009, 42,
1108-1116. (d) Eisenberg, D.; Shenhar, R.; Rabinovitz, M. Synthetic approaches to aromatic belts: building up strain in macrocyclic polyarenes. Chem. Soc. Rev. 2010, 39, 2879-2890.

(4) (a) Grimsdale, A. C.; Müllen, K. Bridged Polyphenylenes - from Polyfluorenes to Ladder Polymers. In Polyfluorenes, Scherf, U.; Neher, D. Eds. Springer Berlin Heidelberg: Berlin, Heidelberg, 2008; pp 1-48. (b) Grimsdale, A. C.; Müllen, K. Phenylene-Based Ladder Polymers. In Design and Synthesis of Conjugated Polymers, Leclerc, M.; Morin, J. Eds. Wiley-VCH, Weinheim, 2010, pp. 227-245.

(5) (a) Grimsdale, A. C.; Müllen, K. Polyphenylene-type Emissive Materials: Poly(para-phenylene)s, Polyfluorenes, and Ladder Polymers. In Emissive Materials Nanomaterials, Springer Berlin Heidelberg: Berlin, Heidelberg, 2006; pp 1-82. (b) Xie, L.-H.; Yin, C.R.; Lai, W.-Y.; Fan, Q.-L.; Huang, W. Polyfluorene-based semiconductors combined with various periodic table elements for organic electronics. Prog. Polym. Sci. 2012, 37, 1192-1264.

(6) Segawa, Y.; Omachi, H.; Itami, K. Theoretical Studies on the Structures and Strain Energies of Cycloparaphenylenes. Org. Lett. 2010, 12, 2262-2265.

(7) Segawa, Y.; Fukazawa, A.; Matsuura, S.; Omachi, H.; Yamaguchi, S.; Irle, S.; Itami, K. Combined experimental and theoretical studies on the photophysical properties of cycloparaphenylenes. Org. Biomol. Chem. 2012, 10, 5979-5984.

(8) (a) Povie, G.; Segawa, Y.; Nishihara, T.; Miyauchi, Y.; Itami, K. Synthesis of a carbon nanobelt. Science 2017, 356, 172-175. (b) Povie, G.; Segawa, Y.; Nishihara, T.; Miyauchi, Y.; Itami, K. Synthesis and Size-Dependent Properties of [12], [16], and [24]Carbon Nanobelts. J. Am. Chem. Soc. 2018, 140, 10054-10059. (c) Cheung, K. Y.; Watanabe, K.; Segawa, Y.; Itami, K. Synthesis of a Zigzag Carbon Nanobelt. ChemRxiv 2020, 10.26434/chemrxiv.12324353.v1.

(9) Cheung, K. Y.; Gui, S.; Deng, C.; Liang, H.; Xia, Z.; Liu, Z.; Chi, L.; Miao, Q. Synthesis of Armchair and Chiral Carbon Nanobelts. Chem 2019, 5, 838-847.

(10) Nishigaki, S.; Shibata, Y.; Nakajima, A.; Okajima, H.; Masumoto, Y.; Osawa, T.; Muranaka, A.; Sugiyama, H.; Horikawa, A.; Uekusa, H.; Koshino, H.; Uchiyama, M.; Sakamoto, A.; Tanaka, K. Synthesis of Belt- and MöbiusShaped Cycloparaphenylenes by Rhodium-Catalyzed Alkyne Cyclotrimerization. J. Am. Chem. Soc. 2019, 141, 14955-14960.

(11) (a) Kayahara, E.; Qu, R.; Kojima, M.; Iwamoto, T.; Suzuki, T.; Yamago, S. Ligand-Controlled Synthesis of [3]and [4]Cyclo-9,9-dimethyl-2,7-fluorenes through Triangle- and Square-Shaped Platinum Intermediates. Chem. Eur. J. 2015, 21, 18939-18943. (b) Liu, Y.-Y.; Lin, J.-Y.; Bo, Y.-F.; Xie, L.-H.; Yi, M.-D.; Zhang, X.-W.; Zhang, H.M.; Loh, T.-P.; Huang, W. Synthesis and Crystal Structure of Highly Strained [4]Cyclofluorene: Green-Emitting Fluorophore. Org. Lett. 2016, 18, 172-175. (c) Li, S.; Aljhdli, M.; Thakellapalli, H.; Farajidizaji, B.; Zhang, Y.; Akhmedov, N. G.; Milsmann, C.; Popp, B. V.; Wang, K. K. Synthesis and Structure of a Functionalized 
[9]Cycloparaphenylene Bearing Three Indeno[2,1a]fluorene-11,12-dione-2,9-diyl Units. Org. Lett. 2017, 19, 4078-4081. (d) Sicard, L.; Jeannin, O.; RaultBerthelot, J.; Quinton, C.; Poriel, C. [4]Cyclofluorene: Unexpected Influence of Alkyl Chain Length. ChemPlusChem 2018, 83, 874-880. (e) Poriel, C.; Sicard, L.; Quinton, C.; Rault-berthelot, J.; Jeannin, O.; Lucas, F.; Bouit, P. A. [n]-Cyclo-9,9-dibutyl-2,7-fluorene $(n=4,5)$ : Nanoring size influence in carbon bridged cyclo-paraphenylenes. Angew. Chem., Int. Ed. 10.1002/anie.202002517.

(12) Friederich, R.; Nieger, M.; Vögtle, F. Auf dem Weg zu makrocyclischen para-Phenylenen. Chem. Ber. 1993, $126,1723-1732$.

(13) While this project is ongoing in our group, Wang and coworkers reported the synthesis of hydrocarbon belts using resorcin[ $n]$ arenes, which represents a breakthrough in this area. (a) Zhang, Q.; Zhang, Y.-E.; Tong, S.; Wang, M.-X. Hydrocarbon Belts with Truncated Cone Structures. J. Am. Chem. Soc. 2020, 142, 1196-1199. (b) Shi, T.-H.; Guo, Q.-H.; Tong, S.; Wang, M.-X. Toward the Synthesis of a Highly Strained Hydrocarbon Belt. J. Am. Chem. Soc. 2020, 142, 4576-4580. (c) Wang, M.-X.; Shi, T.-H.; Tong, S. Construction of Hydrocarbon Nanobelts. Angew. Chem., Int. Ed. 10.1002/anie.202002827.

(14) (a) Stevenson, S.; Rice, G.; Glass, T.; Harich, K.; Cromer, F.; Jordan, M. R.; Craft, J.; Hadju, E.; Bible, R.; Olmstead, M. M.; Maitra, K.; Fisher, A. J.; Balch, A. L.; Dorn, H. C. Small-bandgap endohedral metallofullerenes in high yield and purity. Nature 1999, 401, 55-57. (b) Charlier, J. C. Defects in Carbon Nanotubes. Acc. Chem. Res. 2002, 35, 1063-1069. (c) Segawa, Y.; Yagi, A.; Matsui, K.; Itami, K. Design and Synthesis of Carbon Nanotube Segments. Angew. Chem., Int. Ed. 2016, 55, 5136-5158. (d) Hitosugi, S.; Sato, S.; Matsuno, T.; Koretsune, T.; Arita, R.; Isobe, H. Pentagon-Embedded Cycloarylenes with Cylindrical Shapes. Angew. Chem., Int. Ed. 2017, 56, 9106-9110.

(15) Ogoshi, T.; Kanai, S.; Fujinami, S.; Yamagishi, T.-a.; Nakamoto, Y. para-Bridged Symmetrical Pillar[5]arenes: Their Lewis Acid Catalyzed Synthesis and Host-Guest Property. J. Am. Chem. Soc. 2008, 130, 5022-5023.

(16) Cao, D.; Kou, Y.; Liang, J.; Chen, Z.; Wang, L.; Meier, H. A Facile and Efficient Preparation of Pillararenes and a Pillarquinone. Angew. Chem., Int. Ed. 2009, 48, 97219723.

(17) Hu, X.-B.; Chen, Z.; Chen, L.; Zhang, L.; Hou, J.-L.; Li, Z.-T. Pillar $[n]$ arenes $(n=8-10)$ with two cavities: synthesis, structures and complexing properties. Chem. Commun. 2012, 48, 10999-11001.

(18) (a) Ogoshi, T.; Umeda, K.; Yamagishi, T.-a.; Nakamoto, Y. Through-space $\pi$-delocalized Pillar[5]arene. Chem. Commun. 2009, 4874-4876. (b)
Ma, Y.; Chi, X.; Yan, X.; Liu, J.; Yao, Y.; Chen, W.; Huang, F.; Hou, J.-L. per-Hydroxylated Pillar[6]arene: Synthesis, Xray Crystal Structure, and Host-Guest Complexation. Org. Lett. 2012, 14, 1532-1535.

(19) Myśliwiec, D.; Kondratowicz, M.; Lis, T.; Chmielewski, P. J.; Stępień, M. Highly Strained Nonclassical Nanotube End-caps. A Single-Step Solution Synthesis from Strain-Free, Non-Macrocyclic Precursors. J. Am. Chem. Soc. 2015, 137, 1643-1649.

(20) Spisak, S. N.; Wei, Z.; Darzi, E.; Jasti, R.; Petrukhina, M. A. Highly strained [6]cycloparaphenylene: crystallization of an unsolvated polymorph and the first mono- and dianions. Chem. Commun. 2018, 54, 78187821.

(21) (a) Xia, J.; Jasti, R. Synthesis, Characterization, and Crystal Structure of [6]Cycloparaphenylene. Angew. Chem., Int. Ed. 2012, 51, 2474-2476. (b) Fukushima, T.; Sakamoto, H.; Tanaka, K.; Hijikata, Y.; Irle, S.; Itami, K. Polymorphism of [6]Cycloparaphenylene for Packing Structure-dependent Host-Guest Interaction. Chem. Lett. 2017, 46, 855-857.

(22) Adamska, L.; Nayyar, I.; Chen, H.; Swan, A. K.; Oldani, N.; Fernandez-Alberti, S.; Golder, M. R.; Jasti, R.; Doorn, S. K.; Tretiak, S. Self-Trapping of Excitons, Violation of Condon Approximation, and Efficient Fluorescence in Conjugated Cycloparaphenylenes. Nano Lett. 2014, 14, 6539-6546.

(23) Shukla, M. K.; Leszczynski, J. A density functional theory study on the effect of shape and size on the ionization potential and electron affinity of different carbon nanostructures. Chem. Phys. Lett. 2006, 428, 317 320.

(24) Iwamoto, T.; Watanabe, Y.; Sakamoto, Y.; Suzuki, T.; Yamago, S. Selective and Random Syntheses of [n]Cycloparaphenylenes ( $\mathrm{n}=8-13)$ and Size Dependence of Their Electronic Properties. J. Am. Chem. Soc. 2011, 133, 8354-8361.

(25) (a) Tobe, Y. Non-Alternant Non-Benzenoid Aromatic Compounds: Past, Present, and Future. Chem. Rec. 2015, 15, 86-96. (b) Esser, B. Theoretical analysis of [5.5.6]cyclacenes: electronic properties, strain energies and substituent effects. Phys. Chem. Chem. Phys. 2015, 17, 7366-7372. (c) Hu, P.; Lee, S.; Herng, T. S.; Aratani, N.; Gonçalves, T. P.; Qi, Q.; Shi, X.; Yamada, H.; Huang, K.-W.; Ding, J.; Kim, D.; Wu, J. Toward Tetraradicaloid: The Effect of Fusion Mode on Radical Character and Chemical Reactivity. J. Am. Chem. Soc. 2016, 138, 1065-1077. (d) Maekawa, T.; Ueno, H.; Segawa, Y.; Haley, M. M.; Itami, K. Synthesis of open-shell ladder $\pi$-systems by catalytic C$\mathrm{H}$ annulation of diarylacetylenes. Chem. Sci. 2016, 7, 650-654. (e) Frederickson, C. K.; Rose, B. D.; Haley, M. M. Explorations of the Indenofluorenes and Expanded Quinoidal Analogues. Acc. Chem. Res. 2017, 50, 977-987. 
Table of Contents (TOC)

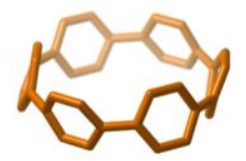

cycloparaphenylene

(carbon nanoring)

- rigid belt

- rapid synthesis

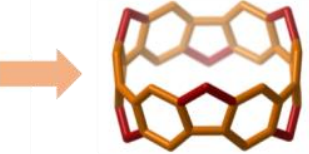

methylene-bridged CPP

(non-alternant aromatic belt)

- narrower energy gap - enhanced $\pi$-conjugation

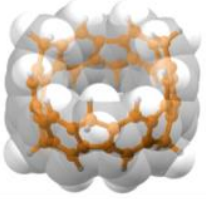

$d x$ 